\begin{tabular}{|c|c|c|}
\hline \multirow{3}{*}{$\begin{array}{r}\text { Case Reports in } \\
\text { Gastroenterology }\end{array}$} & \multirow{2}{*}{\multicolumn{2}{|c|}{ Case Rep Gastroenterol 2013;7:462-466 }} \\
\hline & & \\
\hline & $\begin{array}{l}\text { DOI: 10.1159/000355882 } \\
\text { Publisned online: Uctober 17, } 2013\end{array}$ & $\begin{array}{l}\text { ○ } 2013 \text { S. Karger AG, Basel } \\
\text { 1662-0631/13/0073-0462 } \$ 38.00 / 0 \\
\text { www.karger.com/crg }\end{array}$ \\
\hline & \multicolumn{2}{|c|}{$\begin{array}{l}\text { This is an Open Access article licensed under the terms of the Creative Commons } \\
\text { Attribution-NonCommercial } 3.0 \text { Unported license (CC BY-NC) (www.karger.com/OA } \\
\text { license), applicable to the online version of the article only. Distribution permitted for non } \\
\text { commercial purposes only. }\end{array}$} \\
\hline
\end{tabular}

\title{
Anastomotic Recurrence of Sigmoid Colon Cancer over Five Years after Surgery
}

\author{
Takahiro Yamauchi $^{a}$ Dai Shida ${ }^{a, c}$ Toru Tanizawa ${ }^{b}$ Kentaro Inada ${ }^{a}$ \\ Departments of ${ }^{a}$ Surgery and ${ }^{b}$ Pathology, Tokyo Metropolitan Bokutoh Hospital, and \\ ${ }^{c}$ Colorectal Surgery Division, National Cancer Center Hospital, Tokyo, Japan
}

\section{Key Words}

Anastomotic recurrence $\cdot$ Colon cancer $\cdot$ Local recurrence

\begin{abstract}
The incidence of anastomotic recurrence after curative resection of colorectal cancer is relatively low compared to that of other types of recurrence, such as hepatic, lung and local recurrence. However, almost all cases of anastomotic recurrence of colorectal cancer occur within 3 years after surgery. We experienced a rare case of anastomotic recurrence in whom colonoscopy revealed no signs of recurrence 3 years after surgery; however, anastomotic recurrence was detected over 5 years after surgery. A 60-year-old female with a history of surgery for cancer of the cecum in her forties underwent sigmoidectomy and right colectomy with D3 lymph node dissection for both stage IIA sigmoid colon cancer and stage IIA transverse colon cancer. Computed tomography and colonoscopy revealed no signs of recurrence 3 years after surgery; however, 5 years and 4 months after surgery, colonoscopy demonstrated surrounding flaring and swelling in the anastomotic area of the sigmoid colon, and a biopsy revealed an adenocarcinoma. Under the diagnosis of anastomotic recurrence over 5 years after surgery, lower anterior resection was performed. The patient has exhibited no other signs of recurrence in the 2 years since the last operation.
\end{abstract}

(C) 2013 S. Karger AG, Basel

\section{Introduction}

Anastomotic recurrence of colorectal cancer occurs in approximately $2-15 \%$ of cases [1]. It is thought that cancer cells left in the colorectal tract are implanted following anastomosis [2]. According to the Japanese Society for Cancer of the Colon and Rectum 
(JSCCR) Guidelines 2010 for the Treatment of Colorectal Cancer, anastomotic recurrence occurred in only 22 of all 5,230 (0.4\%) cases reported in the literature. In that study, over $95 \%$ of anastomotic recurrences developed within 3 years after surgery, and only one case occurred after 5 years from the initial surgery [1].

We experienced a case of anastomotic recurrence of stage IIA (T3NOM0) sigmoid colon cancer 5 years and 4 months after surgery. There were no signs of recurrence at the time of surveillance performed 3 years after surgery. The patient was ultimately saved with repeated surgery. Detecting recurrence while the lesion is still resectable can lead to a cure with operative treatment. This emphasizes the importance of conducting surveillance in cases of colorectal cancer, even more than 5 years after curative surgery.

\section{Case Report}

A 65-year-old female had a history of several cancers, including left breast cancer at 36 years of age, cecum cancer in her forties and right breast cancer at 64 years of age. Her mother, younger sister and daughter also each had a history of breast cancer. At 60 years of age, the patient underwent sigmoidectomy and right colectomy with D3 lymph node dissection for both sigmoid colon cancer (fig. 1) and transverse colon cancer. During that operation, lavage of the remnant colon was performed before anastomosis, and automatic anastomotic devices were used. The pathological diagnoses revealed both sigmoid colon cancer and transverse colon cancer of T3N0M0, stage IIA. Both the oral and anal margins of the resected colon had a sufficient length: the transverse margin measured $135 \mathrm{~mm}$ (oral wedge) and $50 \mathrm{~mm}$ (anal wedge), while the sigmoid margin measured $40 \mathrm{~mm}$ (oral wedge) and $50 \mathrm{~mm}$ (anal wedge) (fig. 1a). At 3-year follow-up, colonoscopy and computed tomography revealed no signs of recurrence (fig. 2a). At 5-year follow-up, colonoscopy demonstrated surrounding flaring and swelling in the anastomotic area of the sigmoid colon (fig. 2b). A biopsy revealed an adenocarcinoma. The levels of the tumor markers CEA and CA19-9 were both within the normal limits at that time. There were no signs of recurrence in other locations, such as the liver and lungs, or other areas of the remnant colon. Therefore, under a diagnosis of anastomotic recurrence over 5 years after surgery, we performed lower anterior resection. The tumor measured $45 \times 35 \mathrm{~mm}$ and was located at the previous anastomotic site (fig. 3a). Pathology revealed histological features that resembled the pattern of the previous tumor, and there were masses of cancerous cells in the subserosal and muscular layers near the fissured muscular layer, which comprised the anastomotic area (fig. 3b). In addition, in the mucous membranes surrounding the anastomotic area, there was hyperplasia of cancerous cells that pushed up layers from deeper mucous membranes. Furthermore, there were no cancerous cells in the mucous membranes, which indicated that the cells were derived from the primary lesion (fig. 3b). Based on these observations, the final diagnosis was anastomotic recurrence of sigmoid colon cancer after surgery. No lymph node metastasis was observed among the 18 dissected lymph nodes. There have been no signs of recurrence for the 2 years since the last surgery.

\section{Discussion}

The recurrence rate after curative resection for colorectal cancer depends on the TNM stage of the disease. The recurrence rate among stage I patients is only $3.7 \%$. On the other hand, the recurrence rates among stage II and stage III patients are 13.3 and 30.8\%, 
Yamauchi et al:: Anastomotic Recurrence of Sigmoid Colon Cancer over Five Years after Surgery

respectively [1]. Therefore, a careful follow-up may benefit patients with stage II or III cancer due to the higher recurrence rates observed in such cases.

It is also known that the time to recurrence differs according to the TNM stage. The rate of recurrence has been found to increase gradually and consistently for 5 years in stage I patients, whereas in stage II and III patients, the rate increases rapidly for the first 3 years, then slowly for the next 2 years [1]. Therefore, intensive follow-up programs could be adopted for stage II and III patients for the first 3 years, followed by less intensive follow-up for the next 2 years.

Follow-up programs for patients who have undergone curative resection for colorectal cancer remain controversial. Six randomized controlled trials of intensive versus nonintensive follow-up were recently reported [2-8]. In only two of these studies were there any significant differences in prognosis between the intensive follow-up group and the nonintensive follow-up group [6, 7]. However, meta-analyses including these randomized controlled trials demonstrated that providing intensive follow-up after curative surgery improves survival $[8,9]$.

Compared to other types of recurrence, anastomotic recurrence is relatively easy to detect due to its apparent symptoms, such as bloody bowel discharge. However, in our case, there were no symptomatic signs of recurrence, and the recurrent tumor was detected only on colonoscopy performed as a routine examination 5 years after resection. Therefore, the use of intensive follow-up programs including colonoscopy for 5 years after resection may benefit some populations of colorectal cancer patients.

In conclusion, follow-up after curative resection for colorectal cancer should be continued for at least 5 years and must consist of an intensive follow-up program that includes colonoscopy.

\section{Acknowledgements}

The authors acknowledge all of the nurses who took care of our patient.

\section{Author Contributions}

T. Yamauchi, T. Tanizawa and K. Inada collected the data, administered the treatment and wrote the paper. D. Shida was responsible for writing and supervising the paper.

\section{Disclosure Statement}

There is no conflict of interest.

\section{References}

1 Kobayashi H, Mochizuki H, Morita T, Kotake K, Teramoto T, Kameoka S, Saito Y, Takahashi K, Hase K, Oya M, Maeda K, Hirai T, Kameyama M, Shirouzu K, Sugihara K: Characteristics of recurrence after curative resection for T1 colorectal cancer: Japanese multicenter study. J Gastroenterol 2011;46:203-211.

-2 Ohlsson B, Breland U, Ekberg H, Graffner H, Tranberg KG: Follow-up after curative surgery for colorectal carcinoma. Randomized comparison with no follow-up. Dis Colon Rectum 1995;38:619-626.

-3 Makela JT, Laitinen SO, Kairaluoma MI: Five-year follow-up after radical surgery for colorectal cancer. Results of a prospective randomized trial. Arch Surg 1995;130:1062-1067. 
Yamauchi et al:: Anastomotic Recurrence of Sigmoid Colon Cancer over Five Years after Surgery

4 Kjeldsen BJ, Kronborg 0, Fenger C, Jorgensen OD: A prospective randomized study of follow-up after radical surgery for colorectal cancer. Br J Surg 1997;84:666-669.

5 Schoemaker D, Black R, Giles L, Toouli J: Yearly colonoscopy, liver CT, and chest radiography do not influence 5-year survival of colorectal cancer patients. Gastroenterology 1998;114:7-14.

6 Pietra N, Sarli L, Costi R, Ouchemi C, Grattarola M, Peracchia A: Role of follow-up in management of local recurrences of colorectal cancer: a prospective, randomized study. Dis Colon Rectum 1998;41:1127-1133.

7 Secco GB, Fardelli R, Gianquinto D, Bonfante P, Baldi E, Ravera G, Derchi L, Ferraris R: Efficacy and cost of risk-adapted follow-up in patients after colorectal cancer surgery: a prospective, randomized and controlled trial. Eur J Surg Oncol 2002;28:418-423.

8 Renehan AG, Egger M, Saunders MP, O’Dwyer ST: Impact on survival of intensive follow up after curative resection for colorectal cancer: systematic review and meta-analysis of randomised trials. BMJ 2002;324: 813.

-9 Figueredo A, Rumble RB, Maroun J, Earle CC, Cummings B, McLeod R, Zuraw L, Zwaal C; Gastrointestinal Cancer Disease Site Group of Cancer Care Ontario's Program in Evidence-Based Care: Follow-up of patients with curatively resected colorectal cancer: a practice guideline. BMC Cancer 2003;3:26.
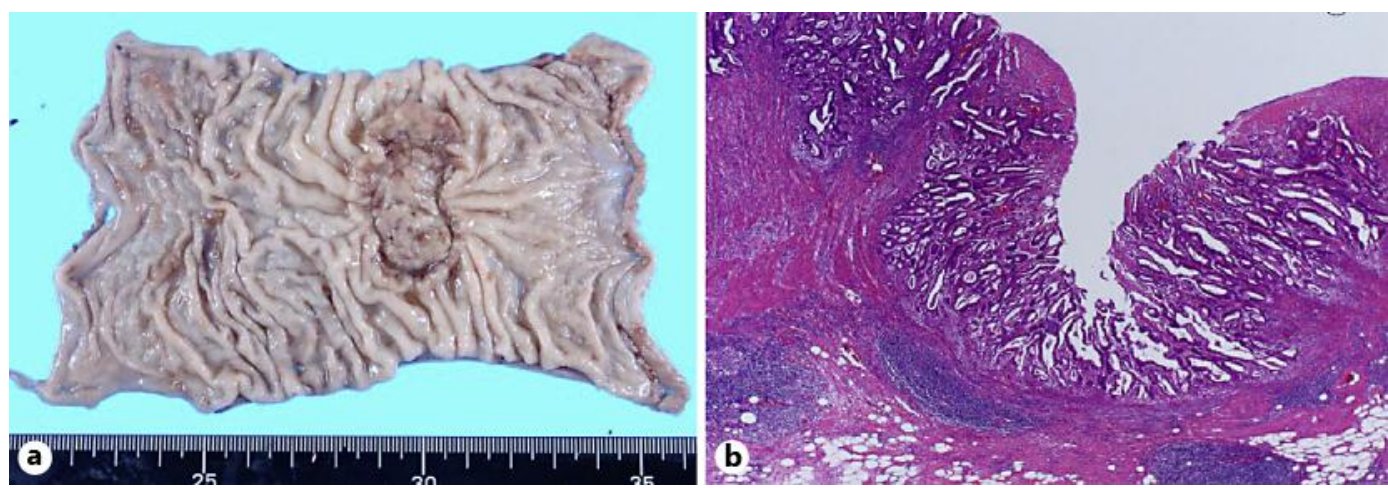

Fig. 1. Primary sigmoid cancer. a Macroscopic appearance of the primary sigmoid colon cancer. b Microscopic appearance of the primary sigmoid colon cancer.
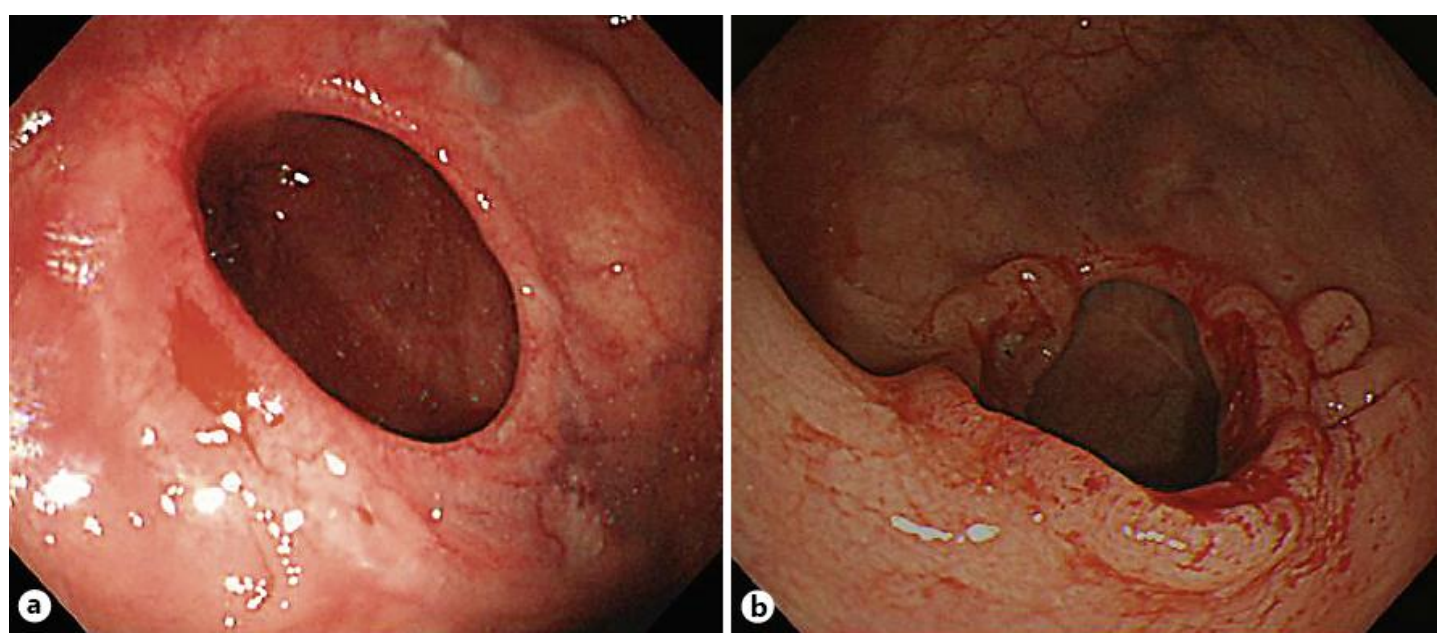

Fig. 2. Follow-up colonoscopy after the primary operation. a Colonoscopy showing no evidence of recurrence at the anastomotic site 3 years after the primary operation. b Colonoscopy showing anastomotic recurrence 5 years after the primary operation. 
Yamauchi et al.: Anastomotic Recurrence of Sigmoid Colon Cancer over Five Years after Surgery
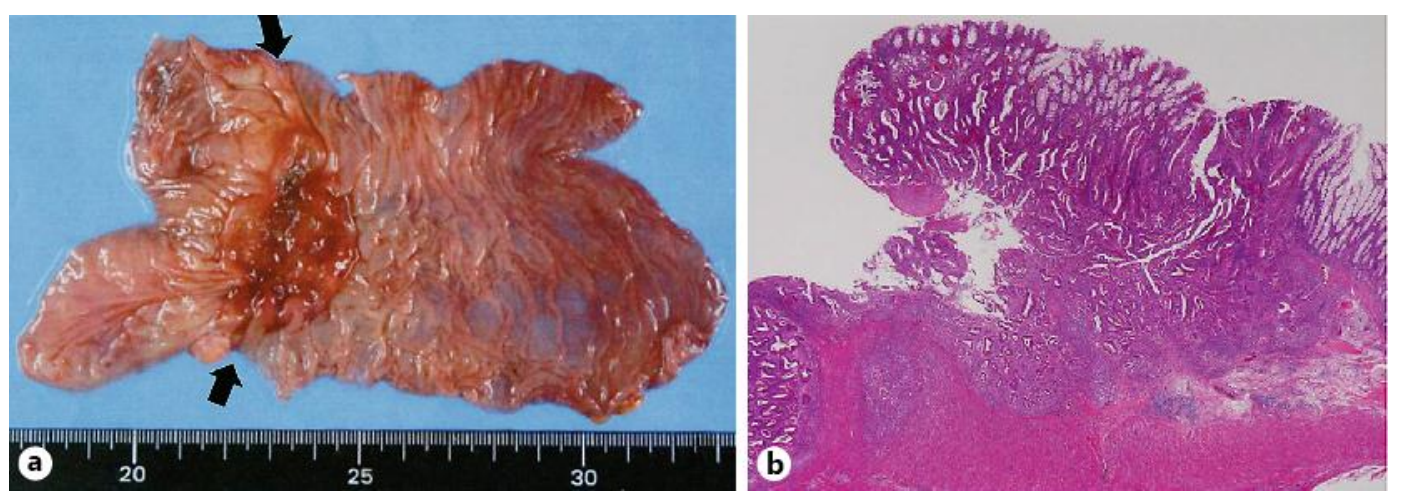

Fig. 3. The resected intestine exhibiting anastomotic recurrence. a Macroscopic appearance of the resected intestine demonstrating anastomotic recurrence. The arrows indicate the previous anastomotic line. b Microscopic appearance of the resected intestine demonstrating anastomotic recurrence. 